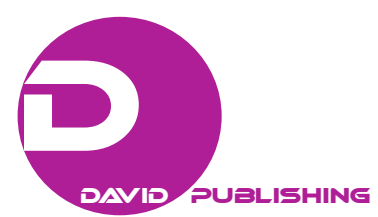

\title{
Pay or Nature? The Relative Weights of Pecuniary Incentives and Course Conditions in IRONMAN Races
}

\author{
Joachim Prinz \\ University of Duisburg-Essen, Duisburg, Germany \\ Phillip Becker \\ University of Paderborn, Paderborn, Germany
}

\begin{abstract}
Most of the studies analyzing the effectiveness of a tournament compensation style use data from an athletic context because data on an individual's income and output are easily available. While the papers illustrate a positive correlation between the level of prize money doled out by the event organizer and athletes' performances the impact of pay on productivity might be biased if other fixed and random components are neglected and left out in the athlete's output function. The aim of this paper is to analyze this bias empirically by using new and detailed information from 62 long-distance triathlon IRONMAN competitions around the world to reassess the motivational aspect of prize money, controlling for course and weather conditions. The results of the OLS data analysis indicate the persistence of the incentive effect provided by remuneration but this effect is mitigated when nature is controlled for.
\end{abstract}

Keywords: tournament compensation, pay-output-correlation, motivation, effort, Triathlon, regression analysis

\section{Introduction}

In recent years the triathlon market recognized its best performance since its inaugural race in Hawaii 1978. In the past season 2015/2016, output grew in terms of new and additional triathlon races as well as finishers all over the world. Much faster than running events (i.e. city-marathons) short- and long-distance triathlon participation rose by 15\%-20\% p.a. Moreover, the International Triathlon Union (ITU) recorded in a recent study that in 2013, more than two million amateur triathlets competed in almost 13,000 contests around the world, spending four billion US\$ worldwide. Given the current hipness, triathlon and especially the long-distance market, have become a booming mass-participation sport. Today, triathlon is seen as a lifestyle development especially lived by non-elite athletes while professional athletes have mostly benefited from this commercialization and globalization of triathlon. As in other individual endurance sports, being a professional triathlete means vying for doled out prize money. Different from athletes in the team sport industry where players receive a contracted and mainly fixed salary, agents from individual sports are more exposed to financial risk since their main income share is paid by prizes and bonuses related to relative performance (tournament setting) to induce athletes to put forth more effort. In this context, the endurance sport of

Joachim Prinz, professor of Economics, University of Duisburg-Essen, Duisburg, Germany.

Phillip Becker, Ph.D. candidate, University of Paderborn, Paderborn, Germany.

Correspondance concerining this article should be addressed to Joachim Prinz, Lotharstraße, 65, Duisburg 47057, Germany. 
Ironman-triathlon has become of interest since most of their income is earned from prize money, doled out from the event organizer IRONMAN. Although, the amount of prize money is comparably low i.e. to city marathon-running, Daniela Ryf and Jan Frodeno had the highest payday in triathlon history in December 2015 after winning the so-called "Triple Crown” tournament by being first at the competitions in Dubai (Ironman 70.3 Dubai), Zell am See (Ironman World Championship 70.3), and Bahrein (Ironman 70.3 Bahrein), cashing in a purse of one million US\$ respectively.

While the incentive effects of tournaments are empirically well documented (Golf and Tennis) only two studies exist in the context of an endurance sport, analyzing whether athletes produce more effort if prize money rewards and pay dispersion are higher and spread more unequal among top contestants. Frick and Klaeren (1997) were the first to investigate the implications made by Lazear and Rosen (1981) using data from City Marathons showing that a higher and (more) hierarchical pay drives marathon runners to input more energy and run faster. These results have been confirmed by Frick and Prinz (2007) with the help of an extended database and simultaneously applying a more elaborated estimation technique.

Albeit these results are interesting in their own, little is known about the incentive effects of prize money in Ironman races where relative little prize money is paid out to athletes. Moreover, and more importantly however, using data from Ironman athletes eliminates the deficits of the Frick and Klaeren (1997) and the Frick and Prinz's (2007) papers: Both studies imply that money incentives put forth more effort making them run faster. However, finishing times are not solely determined by the level of prizes giving room for a potential "omitted variable bias" theoretically proxied as being random. Other determinants such as temperature, current, swell, humidity, head and cross winds, bike and run course do most probably have an (even stronger) impact on finishing times than pecuniary incentives might have. These "contest conditions” provided by nature are particularly pronounced in Ironman races and haven't been looked at in other pay for performance athletic studies. Secondly, prize money is low compared to marathon-running while expenditures (traveling costs, equipment etc.) are much higher, altering the cost-benefit ratio of triathletes. And third, an Ironman race is riskier and more unpredictable (flat tires, swim and bike accident, weather-change) than marathon-running, resulting in the fact that the perceived prize money value is further reduced. From this point of view, all but the prize money coefficient (incentive) should explain the variance of professional triathletes finishing times. Oppositely however, if the prize money coefficient will still be found significant and negative, it implies that even a reduced amount of money urges athletes to put forth more effort even after controlling for factors given by nature.

The remainder of the paper is structured as follows. First, some important milestones regarding the triathlon industry are presented and the supply side of the market is highlighted. In a next step, the demand side of the IRONMAN market is analyzed, putting forth the determinants' of being successful in an event. This chapter is followed by a literature review working out the most important findings of tournaments in an endurance context. The next section presents the data. Using information from 62 global long-distance triathlon races (3.8 km swim; $180 \mathrm{~km}$ bike; $42 \mathrm{~km}$ run) of the IRONMAN-family in 2014 and $2015(\mathrm{n}=464)$ it is found that the typical (economic) performance determinants (prize money and pay dispersion) of endurance athletes (marathon-runners as in Frick \& Klaeren, 1997; Frick \& Prinz, 2007) are considerably reduced if weather and course conditions are plugged into the estimation strategy. The last chapter discusses the findings concludes and displays implications for triathlon organizers. 


\section{The Literature of the IRONMAN Market}

\section{Evolution and Organization of the IRONMAN Market}

Apart from some ultra-sport events triathlon is regarded as one of the world's most admired and exhausting sports (Leper, 2008). This is especially true for the long-distance race, the so-called Ironman. The Ironman consists of three combined endurance legs, $3.8 \mathrm{~km}$ of swimming, $180 \mathrm{~km}$ of cycling and ending with a marathon run. Athletes need to be extremely fit (Knechtle, Wirth, \& Rosemann, 2010). Depending on an athlete's size, the Ironman-triathlete faces energy costs between 8,000-10,000 kcal (Laursen \& Rhodes, 2001). Triathlon's inauguration took place in Honolulu, Hawaii, 1978. Three navy officers tried to analyze whether swimming, biking, or running is supposed to be the world's most endurable sport (Sowell \& Mounts, 2005). Since then, the Ironman triathlon, gained great popularity around the world. Already in 1983 the World Triathlon Cooperation (WTC) was founded. It is the owner of the IRONMANTM and operates by licensing IRONMAN Hawaii qualification contests and slots. This business strategy was the origin of the IRONMAN circus consisting of qualifying races in New Zealand (1985), Japan (1985), Australia (1985), Canada (1987), Germany (1987), Nice (1988), and Lanzarote (1992). From the origin of the IRONMAN family in 1985 the series has grown to 39 races worldwide and most of them are sold out within view days (McCarville, 2007).

Table 1 highlights the current 39 IRONMAN locations all over the world. As can be seen, the table displays average values of almost 150 events between 2011 and 2015. All but Hawaii is qualifying races for the most popular and one of the toughest long-distance triathlon, the annual World Championship in Kona. Here, athletes also perform a $3.8 \mathrm{~km}$ swim, a $180 \mathrm{~km}$ bike ride, and a final marathon within $17 \mathrm{~h}$. Although the widespread races cover the same distance, they are different in terms of course conditions where topography and weather alter the effort level. For example, while IM Lanzarote is well known for its heavy winds and elevated bike split, IM Wales is notoriously known for its cold water temperature while athletes in Malaysia face humidity and temperatures of more than 35 degrees Celsius. On the other hand, the fast performances in Barcelona are principally caused by the fast-track bike course (flat out) and IM Chattanooga provides athletes with a strong current towards the swim finish. Given these differences, provided by mother nature (elevation, winds, water temperature, humidity, ocean swimming etc.) finishing times, the number of starters and drop-outs differs significantly. Additionally, these alterations lead to different levels of prestige within the triathlon community.

Similar to many other sports, triathlon distinguishes between professional and amateur athletes. But similar to a city-marathon age-groupers compete simultaneously with professional athletes. In order to enter the World Championship in Hawaii both groups need to qualify for a slot in Kona.

In order to participate at the World Championship in Hawaii each athlete has to qualify. As in Fomula 1 or Biathlon, elite athletes collect points for the World Championship. In triathlon, this is Kona Pro Ranking (KPR) point system while doing qualifying races. Those who collected most points are ranked in the top 50 professional list and are eligible to participate in Kona. The first athlete crossing the finish line is the Champion. Amateurs follow a different mode. These athletes have to meet the qualifying times in one of the qualifying races (Table 2). However, recreational athletes only compete with peers from the same age group. Depending on the number of athletes running in the respective group a predetermined number of (Hawaii) slots are awarded to the fastest athletes. 
Table 1

Worldwide IRONMAN Race Characteristics (2011-2015, Daily Averages, Taken From Prinz 2017)

\begin{tabular}{|c|c|c|c|c|c|c|c|c|c|c|c|c|}
\hline Races & Outside Temp. & Humidity & Wind in $\mathrm{km} / \mathrm{h}$ & Water Temp. & Salt & Elevation Bike & Elevation Run & Prize Money & $\#$ of Starters & Finishers & Finish Time sec. & Drop Out \\
\hline Lanzarote & 21,8 & 60 & 26,4 & 18,4 & 1 & 2668 & 286 & 25000 & 1824 & 1533 & 32903 & 0,16 \\
\hline France & 22,4 & 69 & 9,4 & 24 & 1 & 2053 & 113 & 75000 & 2682 & 2220 & 31750 & 0,17 \\
\hline Austria & 19,8 & 61 & 5,8 & 23 & 0 & 1771 & 149 & 70000 & 2812 & 2328 & 30068 & 0,17 \\
\hline Frankfurt & 21,6 & 64 & 12,4 & 22 & 0 & 1144 & 372 & 125000 & 2946 & 2289 & 29972 & 0,22 \\
\hline UK & 17,2 & 75 & 13,4 & 16 & 0 & 1877 & 329 & 25000 & 1654 & 1380 & 32923 & 0,16 \\
\hline Switzerland & 20,6 & 75 & 7,8 & 22,2 & 0 & 1550 & 212 & 50000 & 2151 & 1728 & 32076 & 0,19 \\
\hline Maastricht & 18 & 55 & 5 & 16 & 0 & 800 & 120 & 25000 & 877 & 714 & 31699 & 0,19 \\
\hline Sweden & 16,5 & 79 & 11,5 & 19 & 1 & 530 & 312 & 68750 & 2033 & 1732 & 30787 & 0,14 \\
\hline Copenhagen & 17,3 & 77 & 18,3 & 19 & 1 & 633 & 173 & 50000 & 2557 & 2201 & 30559 & 0,13 \\
\hline Vichy & 27 & 33 & 10 & 21 & 0 & 1098 & 132 & 25000 & 1610 & 1186 & 31370 & 0,26 \\
\hline Wales & 14 & 77 & 14,4 & 16 & 1 & 2105 & 499 & 25000 & 1724 & 1361 & 34213 & 0,2 \\
\hline Mallorca & 20 & 70 & 5,5 & 24,5 & 1 & 1538 & 94 & 37500 & 2439 & 1922 & 31235 & 0,21 \\
\hline Barcelona & 19 & 77 & 10,5 & 21 & 1 & 653 & 124 & 50000 & 2522 & 2023 & 29663 & 0,2 \\
\hline Kapstadt & 18,8 & 74 & 16,4 & 20 & 1 & 1800 & 107 & 90000 & 1912 & 1573 & 31286 & 0,17 \\
\hline Taiwan & 18 & 86 & 18 & 24 & 1 & 1735 & 250 & 25000 & 1023 & 815 & 31403 & 0,2 \\
\hline Malaysia & 28 & 84 & 3 & 30 & 1 & 1397 & 88 & 40000 & 927 & 766 & 33320 & 0,18 \\
\hline New Zealand & 14 & 69 & 11,6 & 18 & 0 & 927 & 237 & 55000 & 1401 & 1310 & 31481 & 0,06 \\
\hline Australia & 17,2 & 71 & 13,8 & 21 & 0 & 1255 & 205 & 30000 & 1498 & 1300 & 32180 & 0,13 \\
\hline Melbourne & 16 & 57 & 17 & 18 & 1 & 928 & 109 & 131250 & 2004 & 1717 & 29147 & 0,14 \\
\hline Cairns & 21,5 & 84 & 14,3 & 22 & 1 & 1050 & 87 & 125000 & 1109 & 910 & 31450 & 0,19 \\
\hline W Australia & 22,2 & 50 & 19,8 & 21 & 1 & 227 & 121 & 50000 & 1450 & 1238 & 30780 & 0,14 \\
\hline Texas & 26 & 82 & 23 & 25 & 0 & 756 & 104 & 100000 & 2651 & 2101 & 30497 & 0,2 \\
\hline Lake Placid & 23,2 & 68 & 12,2 & 20,6 & 0 & 1681 & 298 & 20000 & 2780 & 2277 & 33124 & 0,18 \\
\hline Canada & 15 & 65 & 1,67 & 19 & 0 & 1889 & 343 & 75000 & 2009 & 1724 & 32462 & 0,14 \\
\hline Boudler & 23,5 & 41 & 3,5 & 23 & 0 & 1254 & 141 & 12500 & 2764 & 2031 & 32965 & 0,27 \\
\hline Mont-Tremb & 17 & 85 & 2,5 & 21 & 0 & 1882 & 341 & 118750 & 2379 & 2131 & 31810 & 0,1 \\
\hline Japan & 19 & 84 & 16,7 & 21,3 & 0 & 2355 & 283 & 25000 & 1494 & 1197 & 34504 & 0,2 \\
\hline Coeur d'Alene & 18 & 58 & 8,2 & 17 & 0 & 1701 & 286 & 4000 & 2479 & 1947 & 31983 & 0,22 \\
\hline Wisconsin & 17,6 & 71 & 7,6 & 22 & 0 & 1530 & 208 & 2000 & 2797 & 2326 & 32738 & 0,17 \\
\hline Chattanooga & 22 & 79 & 2,5 & 22 & 0 & 1280 & 438 & 75000 & 2512 & 2156 & 30080 & 0,14 \\
\hline Maryland & 16 & 75 & 4 & 22 & 0 & 309 & 59 & 12500 & 2054 & 1371 & 32740 & 0,28 \\
\hline Hawaii & 27,2 & 66 & 12 & 26 & 1 & 1171 & 311 & 636000 & 2117 & 1953 & 30188 & 0,08 \\
\hline Louisville & 24,6 & 63 & 7,6 & 23,6 & 0 & 1374 & 75 & 20000 & 2629 & 2216 & 32939 & 0,15 \\
\hline Los Cabos & 23,3 & 46 & 10 & 28 & 1 & 1578 & 157 & 16666,67 & 1042 & 757 & 32643 & 0,26 \\
\hline Florida & 18,2 & 74 & 11,4 & 21 & 1 & 359 & 48 & 20000 & 2985 & 2406 & 29946 & 0,19 \\
\hline Arizona & 18,4 & 50 & 9,4 & 18 & 0 & 490 & 156 & 80000 & 2949 & 2392 & 29589 & 0,19 \\
\hline Cozumel & 21,4 & 79 & 8,2 & 25 & 1 & 107 & 62 & 80000 & 2266 & 1699 & 30842 & 0,24 \\
\hline Brazil & 17,6 & 78 & 6,6 & 18 & 1 & 777 & 205 & 90000 & 1884 & 1540 & 30312 & 0,18 \\
\hline Fortaleza & 27,5 & 68 & 22 & 27 & 1 & 960 & 126 & 75000 & 894 & 687 & 33204 & 0,22 \\
\hline Summe & & & & & & 48927 & 7760 & 2659916,67 & 79840 & 65157 & 1232831 & \\
\hline & & 68,692307 & & & & & & & & & & \\
\hline Average & 20,1641026 & 7 & 11,1120513 & 21,425641 & & 1254,53846 & 198,974359 & 68202,99154 & 2047,17949 & 1670,69231 & 31611,05128 & 0,18 \\
\hline
\end{tabular}

The Economics of IRONMAN Triathlon: A Theoretical Framework

Being a professional Ironman is a risky choice. Even for elite athletes the sole amount of kilometers doing in a contest is a difficult adventure. Sometimes athletes face temperatures of more than 100 degrees (40 degrees Celsius), making events physically and mentally highly demanding. Moreover, athletes incur considerable direct costs i.e. equipment and out of pocket for travelling expenditures around the world (Wicker, Maxcy, \& Prinz, 2016; Wicker, Prinz \& Weimar, 2013). While input costs are high, output in terms of measurable returns i.e. prize money is low. As in marathon running, elite athletes do not have many opportunities to race competitively during the season since full regeneration from a past and necessary qualifying Ironman race is comparably long (Frick \& Klaeren, 1997; Frick \& Prinz, 2007). Based on the results of 230 Ironman races between 2000 and 2011 Adler (2017) shows that the average number of performed long-distance races is about two a year, which limits the athlete's opportunities making (prize) money. Consequently, triathletes need to select races in order to be successful. Traditionally, the highest return on investment is achieved at the World Championships in Hawaii. Hawaii is the athlete's marquee event. But what are the determinants that drive an athlete's success?

Doing an Ironman triathlon requires an athlete to practice and work out up to 40 hours a week (Adler, 2017; Neumann, Pfützner, \& Hottenrott, 2010). While nonprofessional athletes train approximately $10 \mathrm{~km}$ of 
swimming, $250 \mathrm{~km}$ of cycling, and $50 \mathrm{~km}$ of running elite athletes train considerably more and typically with higher intensity. But apart from training volume and training intensity other factors influence an athlete's performance. In the literature, four theoretical aspects are known that determine an endurance athlete's output. Certainly, biology and predispositions play a major role. As indicated by Coyle (2005) and Suriano and Bishop (2010) these are mainly the maximal oxygen uptake $\left(\mathrm{VO}_{2 \max }\right)$ and the blood lactate threshold, that is, aerobic power. Additionally, it has been shown that small and light riders in a multiple stage cycling race (Swain, 1994) dominate the competition and that successful short-distances triathletes are tall, of medium weight and of low body fat (Sleivert \& Rowlands, 1996). Beside these physical characteristics, high training volume and high intensity training are a necessary condition. Moreover, prerace experience (human capital) seems to be relevant. First, athletes improve their muscular efficiency over time (Coyle, 2005) while simultaneously maturing regarding race tactics and strategic input of limited energy during a long season (Raya, 2015). Although these medical and physical approaches seem to be conclusive, they aren't the sole drivers associated with performance. At least two further approaches influence athletes' productivity which haven't been investigated yet. One is the economic approach, typically observed in sport contests, as provided by tournament theory (Lazear \& Rosen; Ehrenberg \& Bognano, 1996; Lynch \& Zax, 2000). The theory states that a higher prize purse and a more unequal prize money spread motivates athletes to put forth more effort. No matter which sport is considered all competitions are organized in a matter that distinguishes the winner from the looser of the contest. Typically, winners and runner-ups are ordered by ranks illustrating their relative performance among those participating in the game. In order to motivate elite athletes to put forth as much effort as possible the race organizer introduces a pre-determined prize purse distribution depending on the particular rank obtained by the competing athlete. Since the particular amount of received prize money is based on the athlete's final rank, the incentive effect given by the tournament remuneration style is the money spread associated with the ranks. Since the prize money coupled to the particular ranks is known before the race all competing athletes can assess their (additional) purse while moving up the ranks (improving their performance). In this sense, events doling out more and paying a rather unequal prize money distribution to the specific ranks should see better and more motivated athletes, simply because their marginal revenue in climbing up the ranks is higher than in other minor paid races.

The next concern is related to course and location specific conditions affecting athletes' performance by mother nature. Ironman performances are especially influenced by weather conditions and the course attached to a given race. Indeed, water temperature, byoncy, current and chop of the water, air temperature and humidity impair an athlete's output. While it is argued that race conditions affect all athletes at the same time, athletes are heterogeneous i.e. in dealing with cold water temperature, a circumstance that is impossible to adapt in training. Moreover, Ironman races differ in topography and other weather conditions such as wind and heat. Therefore, across races, perfect weather conditions can easily "outperform” incentives provided by prize money aspects as theorized above. In other words, while tournament theory suggests that the income-maximizing athlete should perform best in the race paying out the highest and rather unequal purse this motivational aspect of prize money on performance (finish time) might be biased if other additional determinants impairing an athlete's speed are controlled for. A very illustrative example is the comparison among three long-distance races in Germany and Austria. The European Championship in Frankfurt (IRONMAN Frankfurt) and the long-distance race in Roth (Challenge Roth) as well as the IRONMAN qualifier race in Klagenfurt (IRONMAN Austria), these three races take place in a cultural similar environment. All three races are held 
within two weeks at the beginning of July, implicating that weather conditions are similar. All three events cover the same distance and course conditions are exactly the same. Assuming the predictions made by tournament theory the race in Frankfurt should be the most attractive spot for income maximizing athletes. Not only because Frankfurt is better paid (75,000€ for the top eight ranks) compared to Roth (€36,000 for the top 10; Klagenfurt is $€ 40,000$ for top 10) but more so given the privilege of being a European Championship, attracting high profile triathletes cheered by thousands of people. Further, only participating in an IRONMAN event makes athletes eligible competing at the World Championship in Hawaii, which is not possible in the rival Challenge league in Roth. Nevertheless, running a correlation analysis between prize money and finishing time among athletes competing in Frankfurt and Roth between 2010-2016 $(\mathrm{n}=140)$ indicates the opposite sign (corr. $=+0.183 \mathrm{n} . \mathrm{s}$ ) meaning that athletes perform slower in the prestigious and highly paid event in Frankfurt. Since this observation questions the assumptions made by tournament theory it is necessary to investigate the impact of other fixed and random components driving professional athletes to put forth more effort and to do faster.

Figure 1 displays these four theoretical assumptions. Before these are analyzed empirically a selected review of the prevalent literature of an athlete's output is analyzed.

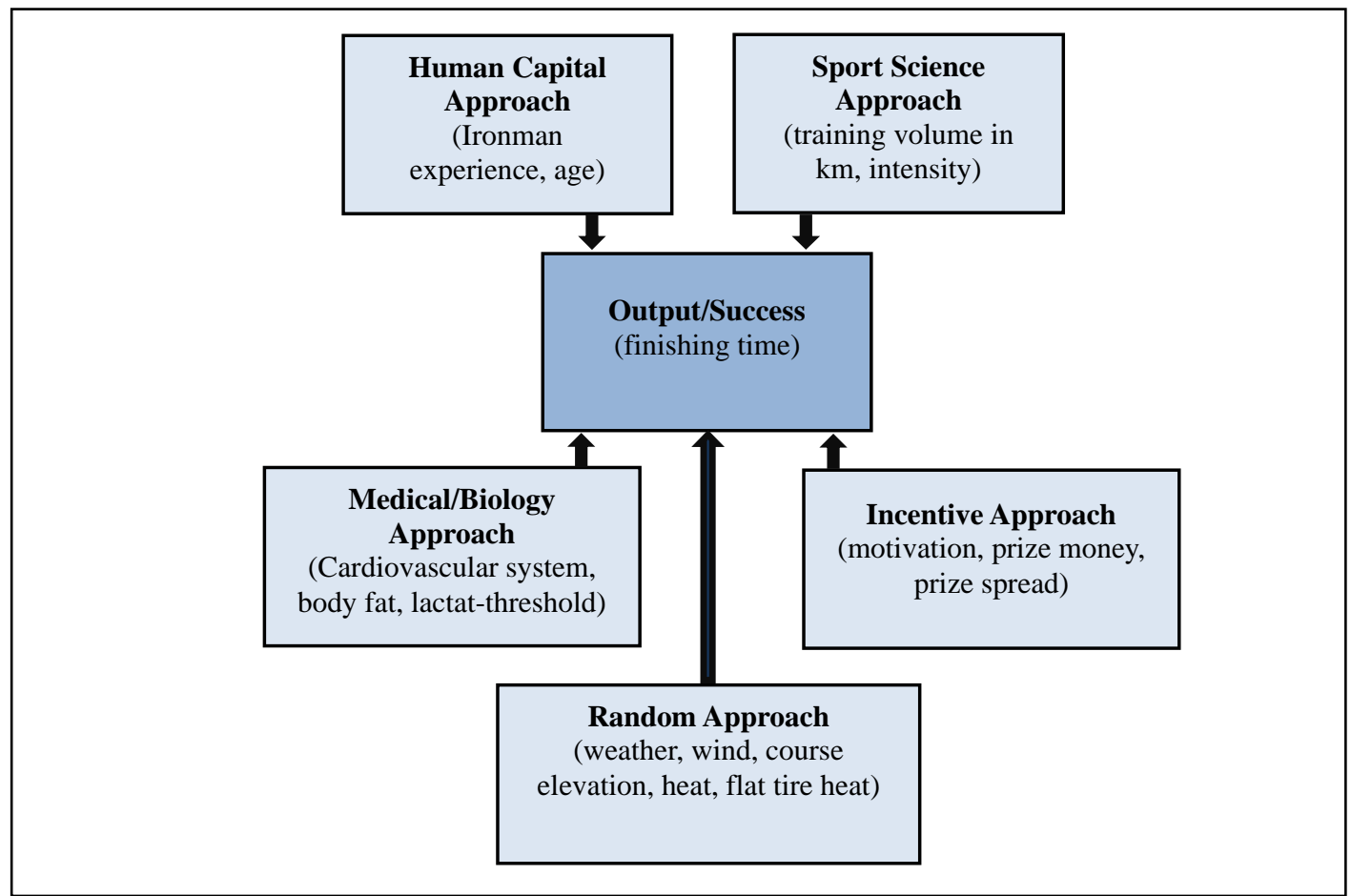

Figure 1. Relevant determinants of IRONMAN triathletes' performance.

\section{Determinants of IRONMAN Performance: A Review of the Evidence}

The majority of existing triathlon papers come from sports scientist and have been published in medical and physiology journals. Generally, these papers investigate productivity development of athletes, distinguishing between gender and different age-groups. Particularly, Ironman data are applied, because they offer many relevant information (output, age, gender etc.) in order to run these investigation (Kahn, 2000; Rosen, \& Sanderson, 2000). Picking this up, Sowell and Mounts (2005) were the first economists using individual data of 111 men and 91 women participating in the 1998 and 1999 Ironman Triathlon World Championships in Kailua-Kona, Hawaii. Expanding the model proposed by Fair (1994) they analyzed the 
human capital model and tested the relationship between an athlete's age and his finishing time. As in Fair (1994) the objective of the study was to estimate the rate of output decline over years. Since athletes are typically recorded in agegroups (five-year increments, male/female) it was possible to use the stochastic frontier estimation technique to determine the most efficient (the fittest) triathlete per age-group. Different from Fair (1994) who used data from track and field (world records) Sowell and Mounts (2005) find that men's output declines faster than other studies implicated but that men's rate of aging is slower than the rates computed for women.

Using data from elite Ironman racers in Hawaii (top $10 \mathrm{~m} / \mathrm{f}$ ) Leper (2008) analyzed the performance of 400 prize money ranked athletes between 1988-2008. Specifically, he examined whether male and female athletes made output improvements (faster finishing times) and whether the magnitude of the gender difference became smaller among the three disciplines (3.8 km-swim; 180 km-cycling; 42 km-run). Leper (2008) used OLS regression and computed the percent difference in time between female and male elite athletes for the three endurance legs separately and collectively. His findings indicate that both sexes improved their overall productivity during the 80s but stayed relatively flat within the 90s until 2007. While both genders increased bike performance women reduced the running gap (compared to men), while the swim difference among the genders remained more or less small. The latter finding is due to females' higher share of body fat.

Performing an observational field study from nonprofessional male Ironman athletes $(n=83)$ in Zurich, 2009 (IRONMAN SITZERLAND 2009), Knechtle, Wirth, and Rosemann (2010) tried to estimate the most relevant determinants of these athletes' output. The aim of their study was to find the most important factor in predicting an agegrouper's performance. Especially, the authors looked at factors, such as body fat, athletes' training volume, and training intensity as well as prerace experience and their personnel best in marathon running. Ceteris paribus, the authors found that high intensity training sessions and an individual's marathon time explain participants performance at the Ironman Zurich best.

Along the same lines Prinz (2017) investigates factors influencing non-elite IRONMAN athletes' performance. However, since it has been observed that there is a relatively large share of "first timers" (rookies $\sim 30-40 \%$ ) he does not analyze triathletes' finishing times but rather whether participants cross the finish-line at all. This is relevant because many athletes' utility function is maximized by finishing first and performing second. This is more so because many first timers - but even older athletes-experience specific stress of the swim start and the congested swim itself can be highly dangerous. Thus, he estimates the drop-out rate of non-professional Ironman triathletes using data from 150 races (IRONMAN) around the world. Findings indicate that swimming in the ocean and the (unexpected) banning of wetsuits raises the drop-out rate. Otherwise, races with elevation (i.e. difficult bike course such as Lanzarote) do not increase Ironman failure.

With the help of prospect theory (Kahnemann \& Tversky, 1979), Maxcy, Wicker, and Prinz (2016) analyzed the motives of recreational triathletes participating in a long-distance race. Given high opportunity costs, equipment expenditures, and especially the pain associated with finishing an Ironman (McCarville, 2007), the authors scrutinize whether such a torture can be explained rationally. Applying an online survey, they collected information of 206 non-elite Ironman athletes in 2015 and asked about their rewards to the "torture". Specifically, respondents were interviewed with respect to their feeling when crossing the finish line and the feeling of that some weeks after "being an Ironman". The authors document that mental torture during the race harms the feeling of happiness but that suffering during the race and then finishing the torture increases happiness. 


\section{Research Methods}

The combination of three different disciplines makes triathlon special. The more so since these disciplines are not necessarily complementary. While a lean and small triathlete might perform well during the running leg and the hills on the bike, his output is comparably low in the flats since drafting is forbidden in long-distance races. Additionally, other factors beyond an individual's talent such as weather might have an impact on the output of athletes. Weather and unexpected weather changes have a much higher impact on long-distance triathlon than i.e. on marathon simply due to its longer duration and thus greater weather variance. As implicated by the literature review given above there are many determinants that influence a triathlete's performance. However, putting different theories together is novel. Hence, the following chapter estimates the relative weights of the above outlined theoretical concerns regarding an athlete's output components.

In order to do so, data determining an athlete's output have been collected. This information tries to proxy the theories displayed in Figure 1. As explained in many studies before, an endurance athlete's performance is mainly determined by his biology. Specifically, endurance is driven by the triathlete's volume of oxygen uptake $\left(\mathrm{VO}_{2 \max }\right)$ and blood lactate threshold. Since the data illustrated below aren't able to measure this variable precisely there is however a fundamental relationship between body mass and $\mathrm{VO}_{2 \max }$. This concept of scaling was first illustrated by Swain (1994) explaining the performance of cyclists. Using facts from allometrics it can be shown that area scales with the square of linear dimensions, while volume and mass scale with the cube of linear dimensions. As long as body shape is similar, taller people have more surface area than shorter people, by a ratio of the square of their relative heights. The relation to an athlete's $\mathrm{VO}_{2 \max }$ is that the capacity to uptake oxygen is limited by the surface area of the lungs and the surface area of the muscle capillaries and the aorta. Consequently, larger persons have higher absolute $\mathrm{VO}_{2 \max }$ in liters/min. Moreover, relative to body mass, the frontal drag (riding on the bike) is greater to small riders than to large athletes, hence larger triathletes have an advantage on flat terrain and especially windy courses. In relative terms their muscles have to overcome less air resistance. This natural advantage of tall people is even more amplified by the weight of relative heavy time trial bikes usually used in long-distance triathlon where drafting is illegal and mountain terrain is not available. Therefore, more massive triathletes have a comparative advantage on the bike course (Note that the advantage shifts to small and light riders during mountain stages because body mass scales with the cube and not the square!).

Apart from these facts an athlete's output depends on diligence and effort during training sessions as well as his strategy to overcome the race. The theory of human capital (Mincer, 1974) postulates that people increase their output by learning on the job. While aging they improve their skills and knowledge by experience. Athletes are mature similarly than conventional employees, by simply increasing their training volume and routine. From this follows that more experienced athletes produce higher output. Economic theory further assumes that money induces incentives to increase effort. This is revealed by tournament theory that states that events doling out more money attract better athletes and that athletes put forth more effort which results in higher output. Besides these determinants environmental circumstances impair athletes output. Particularly, swimming in the ocean and riding in hilly terrain slows down athletes. Cross and headwinds as well as humidity affect athletes' performance but not necessarily in the same manner. Athletes of different size are differently affected by weather conditions. For example, while small and lean athletes cope comparably well during running in the heat, tall athletes do better on the bike in case of (strong) head winds. 
Table 2 displays the information of athletes gathered to test empirically the arguments presented by the different theoretical approaches. The data illustrate individual and event information of 225 (different) elite triathletes $(n=464)$ competing in 37 different IM locations $(n=62)$ between January 2014 and August 2015 all over the world (www.ironman.com). As can be seen from the descriptive statistics (Table 2) events and athletes differ significantly. Races are influenced by the natural conditions and the self-selection of athletes participating in different races. For example, between the slowest (IM Japan) and the fastest competition (IM Brazil) in 2015, there is a time gap of 1:40 $\mathrm{h}$ among the prize money ranked triathletes, which can simply be explained by the tough bike course in the Japanese race. While IM Lanzarote is well known for its windy (40 $\mathrm{km} / \mathrm{h}$ ) and hilly (2,700 climbing meters) conditions slowing down athletes, IM Wales presents a water temperature of only 16 degrees C., while the European Champion race in Frankfurt (IM Frankfurt 2015) was characterized by unexpected hot conditions of up to 40 degrees C. Interestingly, although the drop-out rate even among the pros was significantly higher than in former editions of the Frankfurt race, it was one of the fastest recorded recently, because two of the best triathletes (Jan Frodeno and Sebastian Kienle) battled for the high winner purse delivered by the organizer $(\$ 30,000)$.

Table 2

Descriptive Race and Individual IRONMAN Statistics (2014-2015)

\begin{tabular}{lllll}
\hline Variable & Definition & Mean & Min. & Max. \\
\hline TEMP & Air temperature in C. (daily average across races) & 20 & 10 & 30 \\
WT & Water temperature in C. (daily average across races) & 21 & 16 & 30 \\
HUM & Humidity (daily average) & 70 & 33 & 95 \\
WIND & Wind speed (daily average) & 15 & 2 & 39 \\
WET & Wetsuit allowed (swimming) & 0.8 & 0 & 1 \\
OCEAN & Open water ocean swim & 0.48 & 0 & 1 \\
BIKE & Climbing meters bike & 1,455 & 338 & 2,668 \\
RUN & Climbing meters run & 250 & 88 & 489 \\
HEIGHT & Height in cm & 183 & 160 & 203 \\
WEIGHT & Weight in kg & 73 & 55 & 100 \\
BMI & Body mass index & 22 & 1.13 & 25.8 \\
AGE & Age of athlete & 33 & 24 & 47 \\
EXP & Experience (number of IM races during one's career) & 15 & 0 & 109 \\
MONEY & Prize money (average prize money of ranked athlete, \$) & 5,125 & 500 & 120,000 \\
FT & Finishing time (average time of prize money ranked athlete) & $8: 41 \mathrm{~h}$ & $8: 05 \mathrm{~h}$ & $9: 45 \mathrm{~h}$ \\
\hline
\end{tabular}

Apart from these race specifics, individual characteristics differ across triathletes. This is true for body type and their endowment of acquired human capital. As outlined above, there exists a correlation between an athlete's body mass and endurance capacity. Additionally, more experienced athletes should be able to perform better since they have obtained event specific human and consumption capital. While the average (elite) triathlete has participated in 15 races, the 42-year-old Petr Vabrousek finished more than 100 events. The number of IM events might insofar influence an athlete's performance since it proxies general and specific human capital (Mincer, 1974). More experienced triathletes are more familiar with the IM-circus, have reached higher career training volume and know e.g. the terrain of the parcours or are quicker through transition zones T1 and T2 than less experienced athletes. Different from marathon runners, professional triathletes aren't small and lean. The influence of body weight fighting against gravity is much lower than on running, almost 
unneglectable in swimming and not pronounced in flat terrain of the bike course. Given the assumption that success of an athlete depends on his body type the profile of the average Ironman in the sample reveals that he is $1.82 \mathrm{~m}$ tall and weighs $73 \mathrm{~kg}(\mathrm{BMI}=21.5)$.

Tournament theory postulates that agents are more motivated to put forth effort if prizes are high. The race distributing the highest prize purse is the Championship in Hawaii. The event on big island pays out $\$ 325,000$ for the top 10 ranked sportsmen (the same amount holds for female athletes), averaging to \$32,500 each. Given the natural conditions in Hawaii (cross-winds, heat, humidity, and open water swim) the race isn't supposed to be a fast event, however, given the status of the event the most positive selected group of triathletes participate. Therefore, one of the most grueling events in Triathlon is on average faster $(8: 22 \mathrm{~h})$ than the race in Copenhagen (8:24 h) which is known for its flat bike and running course. Figure 2 displays average prize money of ranked athletes' finish time and all events in the Ironman circus 2014 and 2015.

From the above mentioned issues follows that many (heterogeneous) factors influence an athlete's output (finish time). Certainly, endurance capacity plays the major role but regarding the (prize money ranked) elite level, triathletes should only marginally differ in this aspect. Therefore, other factors are important as well. The following step-by-step estimation technique hence tries to decompose the relative impact of the main determinants explaining an athlete's output. Overall, four consecutive OLS models are estimated whereby an elite athlete's output is measured by his finishing time (FT) of the IM race. In a first step, economic theory related variables such as prize money (MONEY) won and human capital variables (AGE) are incorporated as independent variables. As in Torgler (2007) the next step adds proxies to analyze the effect of physical preconditions on performance (WEIGHT, HEIGHT). Further, ex-ante known topographical variables (BIKE; RUN; OCEAN) are entered into the regression model and finally rather pre-race unknown facts (WIND, WT, TEMP, WET, HUM) are plugged in.

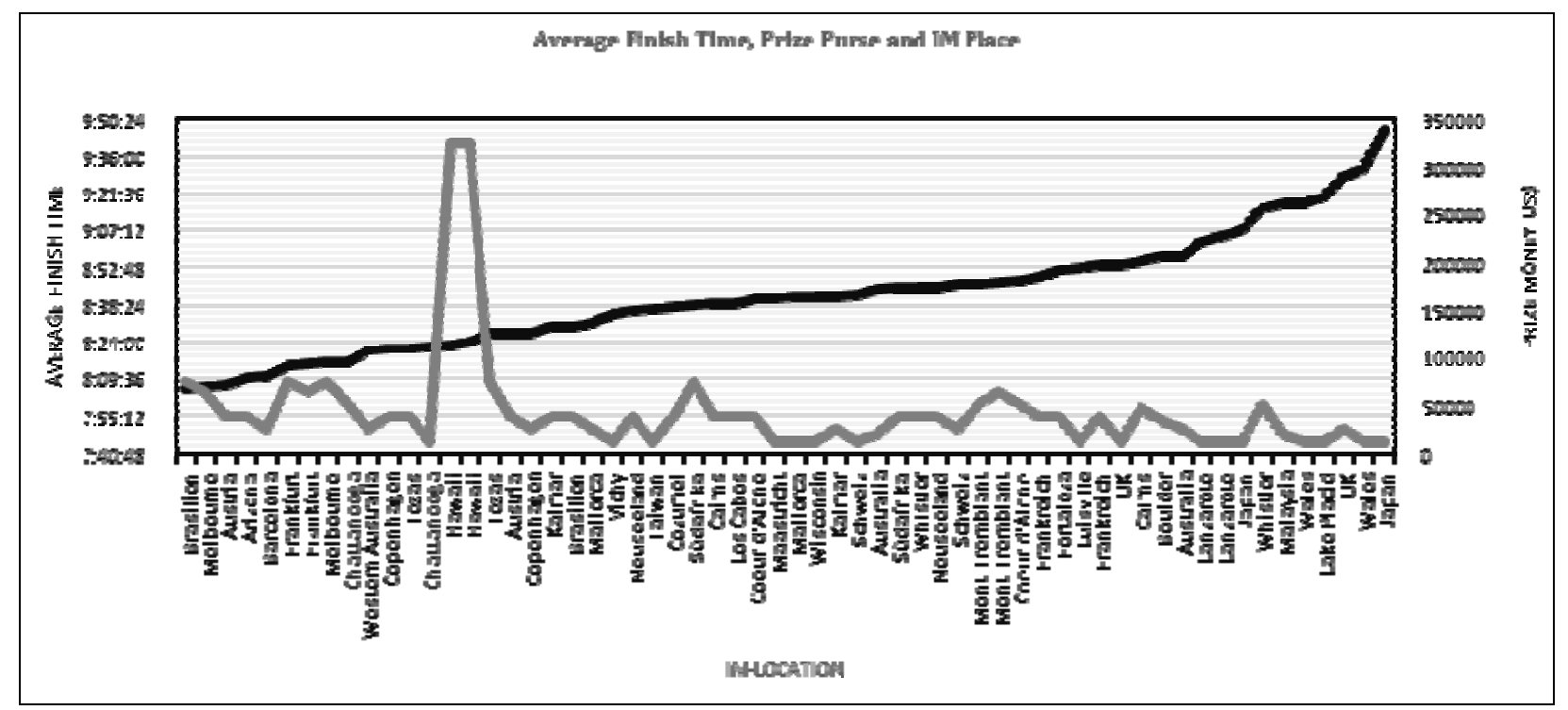

Figure 2. Average ranked finish time, prize money and IM events (Elite Athletes only).

\section{Research Results and Discussion}

The results of the four specifications are presented in Table 3. It reveals the contribution of the independent variables in explaining the variation of the dependent variable finishing time (FT). The preferred 
technique is model 4 since it shows the most likely unbiased estimates. As can be seen, most of the theorized parameters influence triathletes' performance in the predicted manner, that is, these coefficients have the anticipated sign but not all are statistically significant from zero. According to the findings of model 1 more prize money (MONEY) motivates athletes to increase effort in a highly statistical manner. More prestigious races (Championships) pay out more money and attract better athletes. Also, the human capital variables AGE and AGE2 have the anticipated slope but their magnitude is insignificant. Given the sign, older triathletes are faster but the acceleration of age reduces the performance in later years. As known from other endurance sports athletes' output peaks later than is commonly known in e.g. team sports. From the pointwise age coefficients outreged in model 4 can be computed that elite Ironman racers find their peak with age 34.3 years $(-0.01029 / 2$ $\times 0.00015$ ). In the next step (model 2) proxies for testing an athlete's endurance capacity $\left(\mathrm{VO}_{2 \max }\right)$ are inserted in the regression analysis. Lacking highly important factors such as $\mathrm{VO}_{2 \max }$, lactate threshold and i.e. body fat (see Knechtle, Wirth, \& Rosemann, 2010) an athlete's size and weight (HEIGHT, WEIGHT) are used. So far, these individual characteristics haven't been checked in former studies. Surprisingly, both measures are statistically significant and demonstrate that more body mass slows down athletes while taller sportsmen perform significantly better. Additionally, the prize money variable is significantly reduced from 0.03 to 0.023 , when individual characteristics are controlled for.

Table 3

Determinants of Overall Race Performance (Finish Time of 464 Elite Athletes)

\begin{tabular}{lllll}
\hline Variable & Model 1 & Model 2 & Model 3 & Model 4 \\
\hline MONEY & $-0.030(-15.5)^{* * *}$ & $-0.023(-9.61)^{* * *}$ & $-0.024(-8.63)^{* * *}$ & $-0.021(-8.31)^{* * *}$ \\
AGE & $-0.007(-1.13)^{+}$ & $-0.007(-0.87)^{+}$ & $-0.018(-1.70)^{*}$ & $-0.010(-1.28)^{+}$ \\
AGE2 & $0.000(0.96)^{+}$ & $0.000(0.00)^{+}$ & $0.000(1.68)^{*}$ & $0.000(1.29)^{+}$ \\
HEIGHT & $/$ & $-0.001(-2.34)^{* *}$ & $-0.001(-1.47)^{+}$ & $-0.001(-2.61)^{* *}$ \\
WEIGHT & $/$ & $0.002(3.15)^{* * *}$ & $0.001(1.93)^{*}$ & $0.000(2.65)^{* * *}$ \\
BIKE & $/$ & $/$ & $0.000(4.82)^{* * *}$ & $0.000(8.33)^{* * *}$ \\
RUN & $/$ & $/$ & $0.000(3.50)^{* * *}$ & $0.000(2.07)^{* *}$ \\
OCEAN & $/$ & $/$ & $0.016(2.64)^{* * *}$ & $0.020(6.09)^{* * *}$ \\
TEMP & $/$ & $/$ & $/$ & $0.025(3.85)^{* * *}$ \\
WIND & $/$ & $/$ & $/$ & $0.002(6.10)^{* * *}$ \\
HUM & $/$ & $/$ & $/$ & $0.000(1.68)^{*}$ \\
WT & $/$ & $/$ & 0.553 & $-0.008(-5.60)^{* * *}$ \\
R $^{2}$ & 0.30 & 0.333 & $22.16^{* * *}$ & 0.733 \\
F-value & $20.45^{* * *}$ & $25.03^{* * *}$ & $44.61 * * *$
\end{tabular}

Notes. ${ }^{*} p<0.1 ;{ }^{* *} p<0.05 ;{ }^{* *} p<0.01$; robust (White, 1980) standard errors in parentheses.

Model 3 controls for some predetermined factors impairing an athlete's speed. Ironman triathlons can't be organized in big cities as e.g. marathon runs can do. Logistically long-distance triathlons are much more complex because it depends on the infrastructure that makes a swim, a bike, and a run course possible (Prinz, 2017). For example, while marathon runs are typically held in capital cities, Ironman Copenhagen is the only long-distance race organized in a capital. Given these limitations races vary with respect to their topography. Moreover, swimming in the ocean is much more exhausting (salt and current) than swimming in the lake and additionally hampers sighting due to waves. Both, bike and running elevation have been entered into the equation in Table 3. These findings are intuitive because harder courses increase finishing times. Moreover, the 
dummy variable of the OCEAN parameter (OCEAN $=1)$ is significant and positive, implying that tide and chop in the water reduce athletes' velocity.

Finally, model 4 documents the findings of the full and preferred estimation specification, controlling for random components. As suggested by Leper (2008) but so far not controlled for, wind direction, wind velocity, air temperature, and humidity influence output in the three individual legs and thus overall finishing times. The race in Malaysia is prone for high humidity while athletes face rain and cold during the competition in Wales and England. Since weather conditions vary across locations but also within a long 8:00-9:00 hours day it is necessary to control for these exogenous variables. While most of the aforementioned coefficients remain the same the weather variables have the expected sign and are all significantly sloped. Ceteris paribus, tropical climate as i.e. in Hawaii, Japan, or Malaysia makes athletes slowing down. The same is particularly true for wind velocity mitigating triathletes'overall performance. Also, warmer water (WT) is comfortable for athletes because it makes them faster.

\section{Conclusion}

Especially in the past years, triathlon long-distances races have become very popular around the world. Demand and supply increased and the Ironman organizer is constantly adding new events all over the world. However, since the number of participants is constraint to a certain limit the organizer needs to find and select the best spots. One strategic implication from the results documented in the previous chapter is to find new locations that increase the probability to finish the race and to finish the race as fast as possible. Finishing and finishing well is in the interest of the age-group athlete consequently race directors might select a flat and and wind sheltered bike course because cycling is the most relevant discipline. Rival leagues, like the Challenge family or the Ican series might take this aspect into consideration when allocating new events. Since both rivals (Challenge and Ican) are less capitalized compared to the market leader (IRONMAN) this strategy is helpful in acquiring more age-group athletes and staying competitive.

\section{References}

Adler, K. (2017). Rattenrennen im Individualsport-eine Untersuchung in der Sportart Triathlon (Doctoral dissertation, Leipzig University, 2017).

Coyle, E. F. (2005). Improved muscular efficiency displayed as the tour de france champion matures. Journal of Applied Physiology, 98, 2191-2196.

Ehrenberg, R., \& Bognanno, M. (1990). Do tournaments have incentive effects? Journal of Political Economy, 98, 1307-1324.

Fair, R. (1994). How fast do old men slow down? Review of Economics and Statistics, 75, 103-118.

Frick, B., \& Klaeren, R. (1997). Die Anreizwirkungen leistungsabhängiger Entgelte: Theoretische Überlegungen und empirische Befunde aus dem Bereich des professionellen Sports. Zeitschrift für Betriebswirtschaft, 67, 1117-1138.

Frick, B., \& Prinz, J. (2007). Pay and performance in professional road running: The case of City Marathons. International Journal of Sport Finance, 2, 25-35.

Kahn, L. (2000). The sport business as a labor market laboratory. Journal of Economic Perspectives, 14, 75-94.

Kahneman, D., \& Tversky, A. (1979). Prospect theory: An analysis of decision under risk. Econometrica, 47(2), $263-291$.

Knechtle, B., Wirth, A., \& Rosemann, T. (2010). Predictors of race time in male ironman triathletes: Physical characteristics, training or prerace experience? Perceptual and Motor Skill, 111(2), 437-446.

Laursen, P., \& Rhodes, E. (2001). Factors affecting performance in an Ultraendurance Triathlon. Sports Medicine, 31(3), $195-209$.

Lazear, E., \& Rosen, S. (1981). Rank-order tournaments as optimum labor contracts. Journal of Political Economy, 89(5), 841-864.

Leper, R. (2008). Analysis of Hawaii ironman performances in elite triathletes from 1981 to 2007. Medicine \& Science in Sports \& Exercise, 40(10), 1828-1834. 
Lynch, J., \& Zax, J. (2000). The rewards to running: Prize structure and performance in professional road racing. Journal of Sports Economics, 1(4), 323-340.

McCarville, R. (2007). From a fall in the mall to a run in the sun: One journey to Ironman triathlon. Leisure Science, 29, $159-173$.

Mincer, J. (1974). Schooling, experience, and earnings. New York: National Bureau of Economic Research, Columbia University Press.

Neumann, G., Pfützner, A., \& Hottenrott, K. (2010). Das große Buch vom Triathlon. Aachen: Meyer \& Meyer.

Prinz, J. (2017). Whoever finishes first, we'll call him the Ironman-Standortattraktivität und Nachfrage von Ironman-Rennen. In S. Kirmße and S. Schüller (Eds.), Aktuelle Entwicklungslinien in der Finanzwirtschaft-Teil 1. Frankfurt am Main, Fritz Knapp.

Raya, J. (2015). The effect of strategic resting in professional cycling: Evidence from the Tour de France and the Vuelta a España, European Sport Management Quarterly, 15(3), 323-342.

Rosen, S., \& Sanderson, A. (2000). Labor markets in professional sports. Economic Journal, 111(469), 47-68.

Sleivert, G., \& Rowlands, D. (1996). Physical and physiological factors associated with success in the triathlon. Sports Med, 22(1), 8-18.

Sowell, C., \& Mounts, S. (2005). Ability, age and performance: Conclusions from the Ironman Triathlon World Championship. Journal of Sports Economics, 6(1), 78-97.

Suriano, R., \& Bishop, D. (2010). Physiological attributes of triathletes. Journal of Science and Medicine in Sport, $13,340-347$.

Swain, D., Coast, R., Clifford, P., Miliken, M., \& Stray-Gundersen. (1987). Influence of body size on oxygen consumption during bicycling. Journal of Applied Physiology, 62, 668-672.

Swain, D. (1994). The influence of body mass in endurance bicycling. Medicine and Science in Sports and Exercise, 26(8), 58-63.

Torgler, B. (2007). "La Grande Boucle”: Determinants of success at the Tour de France. Journal of Sports Economics, 8(3), 317-331.

White, H. (1980). A heteroskedasticity-consistent matrix estimator and a direct test for heteroskedasticity. Econometrica, 48(4), 817-838.

Wicker, P., Maxcy, J., \& Prinz, J. (2016). Happiness as a reward for torture: Is participation in a long distance race a rational choice? (Unpublished Manuscript). Sporthochschule Cologne.

Wicker, P., Prinz, J., \& Weimar, D. (2013). Big spenders in a booming sport: Consumption capital as a key driver of triathletes's sport-related expenditure. Managing Leisure, 18(4), 286-299. 